Zarco-Alpuente, A., Ciudad-Fernández, V., Ballester-Arnal, R., Billieux, J.,Gil-Llario, M. D., King, D. L., MontoyaCastilla, I., Samper, P., \& Castro-Calvo, J. (2021). Problematic internet use prior to and during the COVID-19 pandemic. Cyberpsychology: Journal of Psychosocial Research on Cyberspace, 15(4), Article 1.

https://doi.org/10.5817/CP2021-4-1

\title{
Problematic Internet Use Prior to and During the COVID-19 Pandemic
}

\author{
Alfredo Zarco-Alpuente ${ }^{1 *}$, Víctor Ciudad-Fernández ${ }^{2 *}$, Rafael Ballester-Arnal ${ }^{3}$, Joël Billieux ${ }^{4}$, María Dolores Gil- \\ Llario ${ }^{5}$, Daniel L. King ${ }^{6}$, Inma Montoya-Castilla², Paula Samper ${ }^{1}$, \& Jesús Castro-Calvo ${ }^{2}$ \\ ${ }^{1}$ Department of Basics Psychology, Faculty of Psychology, University of Valencia, Valencia, Spain \\ 2 Department of Personality, Assessment, and Psychological Treatments, Faculty of Psychology, University of Valencia, \\ Valencia, Spain \\ ${ }^{3}$ Department of Basic and Clinical Psychology and Psychobiology, Jaume I University, Castelló de la Plana, Spain \\ ${ }^{4}$ Institute of Psychology, University of Lausanne, Lausanne, Switzerland \\ ${ }^{5}$ Department of Developmental and Educational Psychology, University of Valencia, Valencia, Spain \\ ${ }^{6}$ College of Education, Psychology, and Social Work, Flinders University, Adelaide, Australia \\ ${ }^{*}$ Both authors have contributed equally to this work and are willing to share first authorship.
}

\begin{abstract}
The health and socio-economic challenges arising from the COVID-19 pandemic have led to greater reliance on the internet to meet basic needs and responsibilities. Greater engagement in online activities may have negative mental and physical health consequences for some vulnerable individuals, particularly under mandatory selfisolation or 'lockdown' conditions. The present study investigated whether changes in levels of involvement in online activities during the COVID-19 pandemic (i.e., watching TV series, online sexual activities, video games, social networks, gambling, online shopping, and instant messaging) were associated with problematic internet use, as well as whether certain psychological risk factors (positive/negative affect and impulsivity) were significant predictors of these changes. A total of 1,275 participants (66.1\% female, aged between 18-55 years) completed an online survey while in lockdown in Spain (April 15th-23rd, 2020). The survey assessed current engagement in seven different online activities and their engagement prior to the COVID-19 pandemic, as well as psychological risk factors (affect and impulsivity). Most participants (between 60.8\%-98.6\% depending on the activity) reported no changes in participation in online activities, but there was a significant increase in weekly internet use (between 25 and $336 \mathrm{~min}$ ). However, increased internet use was not accompanied by a corresponding increase in problematic use, except for problematic TV series watching and video gaming. Psychological risk factors considered in the study (affect, impulsivity traits) were largely minor or non-significant predictors. Thus, increased internet use during the lockdown in Spain was not related to a proportional growth in problematic usage, suggesting that these behavioral changes may constitute adaptive coping strategies in the context of the pandemic.
\end{abstract}

Keywords: COVID-19; online activity; problematic internet use; risk factors; cross-sectional study

\section{Introduction}

The novel coronavirus (COVID-19) pandemic has caused major disruption to daily life and unprecedented global health and economic challenges (World Health Organization [WHO], 2020a). With no vaccine or effective treatments at the time of the study, the most effective method to contain the contagion and protect individuals was to apply spatial distancing (Abel \& McQueen, 2020). To ensure the efficacy of this approach, governments 
encouraged individuals in avoiding social contact through public health measures (such as temporary closures of schools and universities, shops and leisure centers, limitations in the use of public transport, promotion of home office, etc.). In many countries, these measures were articulated under complete lockdowns. The strictness, duration, and conditions of these lockdowns greatly varied between countries (Hale et al., 2021), but typically involved mandatory home confinement and complete restriction of public activities. Under these conditions, many relied on internet activities to meet basic needs (socializing, access to food and medical services) and meet work and other responsibilities.

Fear of contagion and its consequences (Ornell et al., 2020; Schimmenti et al., 2020), along with major lifestyle changes (e.g., reduced physical exercise and face-to-face socializing) associated with self-isolation or lockdown, can have a significant negatively impact on mental health (Brooks et al., 2020). People quarantined are known to experience increased negative emotions (e.g., fear, anger, confusion), problems in sleep regulation (mainly anxiety-induced insomnia), somatic symptoms (e.g., myalgia, headaches, or dizziness), unhealthy lifestyle patterns (e.g., alcohol consumption, sedentary lifestyle), and/or increased anxiety and depression (Brooks et al., 2020; Sandín et al., 2020; Shigemura et al., 2020; Wang et al., 2020). Furthermore, stay-at-home policies increase the time spent alone at home which can foster loneliness (particularly if living alone), increased social isolation (e.g., from partners, family members, friends) or exacerbate existing relationship conflicts.

Spatial distancing and lockdown policies have had a major influence on Information and Communication Technologies (ICTs) usage patterns. On the one hand, the internet has facilitated adaptation to the many challenges created by the COVID-19 pandemic, helping to mitigate its psychosocial impact by: (a) keeping people distracted from boredom due to loss of routine (e.g., online gaming and video streaming services) (King et al., 2020); (b) receiving important pandemic-related updates (e.g., online news) (Wiederhold, 2020); (c) enabling work and study from home; or (d) communication with relatives and friends (e.g., instant messaging or social networks). Despite this utility, increased internet use may have potential risks associated with excessive usage patterns of ICTs (Király et al., 2020), which could negatively affect physical and mental well-being in vulnerable individuals. King et al. (2020) have speculated that excessive gaming behaviors developed under lockdown conditions could become habitual for some users, leading to difficulties in restoring behavior to pre-lockdown levels. Similarly, Mestre-Bach et al. (2020) propose that individuals with existing problematic pornography use may be vulnerable to increasing their use under lockdown conditions. Recognizing these issues, international health authorities (e.g., WHO or UNICEF), with support of the wider heath community of researchers and clinicians, have proposed strategies to prevent excessive screen time and problematic internet use during the COVID-19 pandemic (Király et al., 2020; UNICEF, 2020; WHO, 2020b). However, these guidelines or suggestions have been guided by an evidence base developed prior to the pandemic, which conceptualizes overuse of online activities in a very different context (Fineberg et al., 2018). Empirical evidence on problematic internet use obtained in the context of pandemic-related lockdown is currently lacking and urgently needed.

\section{The Present Study}

The present study aimed to measure involvement in online activities prior to and during the COVID-19 pandemic, and to assess whether any potential increase in use was associated with higher reported problematic use. An online survey was conducted among a self-selected sample of Spanish residents. Spain has been among the most pandemic-affected European countries and thus represents a useful region to examine changes in internet-related activities. Given their implication in academic commentary and studies of problematic internet use (Baggio et al., 2018; Montag et al., 2019; Starcevic \& Aboujaoude, 2017), this study focused on specific online activities (i.e., online TV series, online sexual activities, video games, social networks, gambling, online shopping, and instant messaging) regardless of the particular device employed to access to these online activities (e.g., smartphone or laptop). Time spent per week was measured as an indicator of the level of engagement in these behaviors, whereas problematic use was measured through a series of specific items measuring: (a) self-perceived excessive time invested in the behavior; (b) interpersonal problems due to the behavior; (c) personal impairment; and (d) self-perceived addictive use. It was hypothesized that internet use would be greater during the COVID-19 pandemic, and that this increased internet use would be associated with higher rates of problematic internet use.

The study included psychometric questionnaires assessing two psychological risk factors well known to influence online behaviors: i.e., positive/negative affect and impulsive personality traits (Billieux \& Van Der Linden, 2012; 
Brand et al., 2019). These potential risk/protective factors were measured as predictors for changes in online behaviors and aimed at identifying relevant targets for prevention actions and/or psychological interventions. In pre-pandemic contexts, multiple studies reported a robust relationship between affect (in particular, negative affect and emotion dysregulation), impulsivity (especially, negative urgency), and an increased risk for problematic internet use (MacLaren et al., 2011; Ostinelli et al., 2021; Velotti et al., 2021). Preliminary data from studies conducted during the COVID-19 pandemic also showed significant relationships between emotional symptoms (anxiety, stress, and/or depression), impulsivity, and heightened internet use (Albertella et al., 2021; Boursier et al., 2020, 2021; Gecaite-Stonciene et al., 2021; Giardina et al., 2021; Sharman et al., 2021; Teng et al., 2021). These studies suggest that exacerbated emotional problems derived from the pandemic and prolonged isolation, along with a certain predisposition to act rashly when facing negative emotional states, may increase the risk for problematic internet use. Therefore, it was hypothesized that increased negative affect (e.g., boredom, monotony) and trait impulsivity (especially, negative urgency) would be associated with increased internet use in the Covid19 context.

\section{Method}

\section{Participants and Procedure}

On 14th March, the Spanish government ordered a restrictive lockdown. By April 15th, Spain was one of the most affected European countries in terms of COVID-19 confirmed cases and deaths (177,644 and 18,708, respectively). During lockdown, citizens were permitted to leave their homes for essential tasks only (e.g., shopping for essential supplies). Participants were recruited between April 15th and April 23rd, 2020. At such time, participants were 30 days into the lockdown period. The research was conducted through an online secured platform, and participants were enrolled through banners posted on social networks (Facebook and Instagram). Inclusion criteria to access the survey were (1) aged over 18 years old and (2) residents in Spain. The average time to complete the study was $20.7 \min (S D=11.1)$. Participants did not receive any compensation for their participation.

A total of 1,789 participants accessed the survey. Initial data derived from the online platform were screened to avoid duplicitous, inconsistent, and/or unreliable responses (e.g., participants reporting > 100 years old). Only those participants who completed $80 \%$ of the survey were included. The final sample consisted of 1,275 participants $(66.1 \%$ females) aged between $18-55$ years old $(M=26.23, S D=9.64)$. Table 1 reports participants' characteristics.

\section{Measures}

\section{Participant Characteristics}

Participants were asked to provide their gender, age, marital status, education, and occupational status. Participants were asked about their availability of devices (computer, tablet, smartphone, smart TV, and games console). Participants were asked about their lockdown conditions: i.e., estimated days spent in lockdown, degree of compliance with the lockdown, number of cohabitants, and physical size of their residence. Finally, participants answered three questions assessing self-perceived negative impact of lockdown on: (a) mental health; (b) personal finances; and (c) relationships quality with the people they were living with.

\section{Internet Use Before and During the COVID-19 Pandemic}

Internet use before the COVID-19 pandemic was assessed retrospectively. Participants were asked questions in reference to the two-week period preceding the COVID-19 lockdown (i.e., 1st to 14th of March). To assess internet use during the COVID-19 pandemic, participants were asked to answer based on the past week. For each online activity, participants were first asked about engagement in that activity (yes/no) prior to and during the pandemic. For each online behavior in which participants were involved, further questions were asked. Questions assessing past engagement were preceded by "before the COVID-19 pandemic..." and formulated in past tense; question assessing current engagement were preceded by "during the COVID-19 pandemic..." and formulated in present tense. The questions were the following: (a) time per week ("how much time per week did/do you spend in this 
activity?" [min]); (b) excessive use ("did/do you think you spent more time than you should in this activity?"); (c) interpersonal problems ("did/does someone from your familiar or social circle complain about the amount of time you invested in this activity?"); (d) functional impairment ("did/do you experience significant problems derived from your engagement in this activity (e.g., significant personal distress, avoiding familiar, work, or academical responsibilities, neglecting basic activities -sleep, eating, personal hygiene- or giving precedence to the activity over other life interests and daily activities)?"); and (e) self-perceived addictive use ("did/do you believe you were/are addicted to this activity?"). These questions were designed ad hoc for the present study based on past research having operationalized key features to consider when assessing problematic and addictive online behaviors (Billieux et al., 2019; Kardefelt-Winther et al., 2017).

Table 1. Participants' Characteristics.

\begin{tabular}{|c|c|}
\hline & $\%(n)$ or $M(S D)$ \\
\hline \multicolumn{2}{|l|}{ Demographics } \\
\hline \multicolumn{2}{|l|}{ Gender } \\
\hline Men & $33.9 \%(n=432)$ \\
\hline Women & $66.1 \%(n=843)$ \\
\hline Age $($ range $=18$ to 55 years old $)$ & $26.23(9.64)$ \\
\hline \multicolumn{2}{|l|}{ Marital status } \\
\hline Single & $49.7 \%(n=628)$ \\
\hline In a relationship (not married) & $37.0 \%(n=467)$ \\
\hline In a relationship (married) & $11.7 \%(n=148)$ \\
\hline \multicolumn{2}{|l|}{ Education } \\
\hline Vocational training & $28.4 \%(n=355)$ \\
\hline College or university graduate & $54.6 \%(n=682)$ \\
\hline Post-graduate degree (MA, PhD, etc.). & $12.3 \%(n=154)$ \\
\hline \multicolumn{2}{|l|}{ Occupational status } \\
\hline Student & $66.4 \%(n=847)$ \\
\hline Active worker & $27.0 \%(n=344)$ \\
\hline Unemployed & $9.3 \%(n=114)$ \\
\hline Short-time work scheme ${ }^{a}$ & $8.9 \%(n=118)$ \\
\hline \multicolumn{2}{|l|}{ Accessibility } \\
\hline \multicolumn{2}{|l|}{ Availability of technological devices } \\
\hline Computer (desktop computer and/or laptop) & $80.3 \%$ \\
\hline Tablet & $38.4 \%$ \\
\hline Smartphone & $94.0 \%$ \\
\hline Smart TV & $54.6 \%$ \\
\hline Games console & $33.8 \%$ \\
\hline \multicolumn{2}{|l|}{ Lockdown } \\
\hline Days in lockdown (range $=17-46)$ & $32.37(4.23)$ \\
\hline Lockdown compliance (from 1 [complete compliance] to 6 [not compliance at all]) & $1.94(0.84)$ \\
\hline Number of people cohabiting with (range $=0$ to 9) & $3.34(1.18)$ \\
\hline Home size (from 1 [limited] to 6 [spacious]) & $3.21(0.89)$ \\
\hline \multicolumn{2}{|l|}{ Self-perceived negative impact of lockdown (from 1 [not at all] to 10 [extremely]) } \\
\hline On mental health & $5.24(2.42)$ \\
\hline On personal finances & $4.50(3.07)$ \\
\hline On relationships quality with people I live with & $4.04(2.63)$ \\
\hline
\end{tabular}

Note. Categories with less than $3 \%$ of responses were not included in the table; ${ }^{a}=$ Short-time work scheme (aka, short-time compensation) is a subsidy for workers that have been temporary fired in firms affected by the COVID-19 pandemic.

\section{Psychological Factors}

Mood states in the context of lockdown were assessed by the Spanish version of the Positive and Negative Affect Schedule (PANAS, Sandín et al., 1999). The PANAS consists of two 10-item subscales measuring positive (e.g., interested, excited) and negative affect (e.g., distressed, upset). Participants were asked to rate the extent to which 
these adjectives represented their current mood state, on a 5-point Likert scale ranging from 0 (very slightly or not at all) to 5 (very much). Internal consistency for this scale was .89 (positive affect) and .81 (negative affect) in its Spanish adaptation. In our study, Cronbach's alphas were .89 and .87, respectively.

Trait impulsivity was measured through the Spanish version of the Short Impulsive Behavior Scale (s-UPPS-P, Cándido et al., 2012). The s-UPPS-P is a 20-item scale assessing five domains of impulsivity: (a) negative urgency; (b) positive urgency; (c) lack of premeditation; (d) lack of perseverance; and (e) sensation seeking. Items are rated on a 4-point Likert scale ranging from 1 (strongly agree) to 4 (strongly disagree). In the Spanish adaptation, internal consistency ranged from .66 to .81. In our study, Cronbach's alpha value ranged from .65 (positive urgency) to .81 (sensation seeking). Given that positive urgency was below the threshold of .70 to consider a factor reliable (Hunsley \& Mash, 2008), this domain was not considered for the study analyses.

\section{Data Analysis}

First, we compared engagement in each online activity before and during the COVID-19 pandemic. Four types of users were identified: (a) those who did not engage in a particular online activity at any time ("non-users"); (b) those who engaged in a specific online activity before and during the COVID-19 pandemic ("users"); (c) those who formerly engaged in an online activity but not in the context of lockdown ("stoppers"); and (d) those who did not engage in a specific online activity before but started in the context of lockdown ("starters"). Participants' characteristics according to each profile (in terms of sociodemographic information, impact of lockdown, and scores on the PANAS and the s-UPPS-P) were then presented and compared through $\chi^{2}$ tests (for categorial variables) and one-way ANOVAs (continuous variables).

Among the "user" participant type, we employed paired samples t tests and McNemar tests to compare the following variables before and during lockdown: (a) time commitment in each online activity, (b) excessive time investment, (c) interpersonal conflicts; (d) functional impairment; and (e) self-perceived addictive use. Indicators of problematic internet use were grouped together to create a single aggregated risk score. By subtracting the aggregated risk scores before and during the COVID-19 pandemic, we obtained a single indicator of change in risk of problematic use for each online activity during the pandemic (" $\Delta$ risk"). A change in time investment in each online activity was also computed using this method (labelled " $\Delta$ time"). These two variables ( $\Delta$ risk and $\Delta$ time) were employed as dependent variables in stepwise linear regressions to assess the predictive power of different independent variables (negative affect and impulsivity). The Variance Inflation Factor (VIF) of the estimated linear regression models was inspected in order to check for multicollinearity (as indicated by VIF coefficients $>4$ ) (O'Brien, 2007); no multicollinearity was found.

\section{Results}

\section{Engagement in Online Activities During the COVID-19 Pandemic}

Table 2 shows the percentage of participants according to their profile of engagement in online activities during the COVID-19 pandemic. Most participants (between 60.8\%-98.6\% depending on the online activity) did not report any change regarding their engagement in online activities (i.e., were "users" or "non-users"). The percentage of "new users" ranged from $0.3 \%$ (instant messaging) to 15.8\% (videogames); whereas the percentage of "stoppers" ranged between $1.1 \%$ (instant messaging) and 34.7\% (online shopping). Participants' characteristics according to each profile (sociodemographic information, impact of lockdown, and scores on the PANAS and the s-UPPS-P) are reported and compared in Tables S1-S7. In general, differences between profiles were more prominent when comparing "non-users" with "users" and "new users": in particular, "non-users" were older than "users" (5 out of 7 online activities explored) and "new users" (3 out of 7), tended to report a lower impact of COVID-19 lockdown on mental health and/or personal finances, and showed a better mood (more positive affect and less negative affect). 


\begin{tabular}{|c|c|c|c|c|c|c|c|}
\hline & $\begin{array}{c}\text { TV } \\
\text { Series } \\
\end{array}$ & $\begin{array}{c}\text { Online Sexual } \\
\text { activities }\end{array}$ & $\begin{array}{l}\text { Video } \\
\text { games }\end{array}$ & $\begin{array}{c}\text { Social } \\
\text { networks }\end{array}$ & Gambling & $\begin{array}{c}\text { Online } \\
\text { shopping }\end{array}$ & $\begin{array}{c}\text { Instant } \\
\text { messaging }\end{array}$ \\
\hline \multicolumn{8}{|l|}{ No change } \\
\hline Non-users ${ }^{a}$ & $8.5 \%$ & $64.3 \%$ & $47.3 \%$ & $4.5 \%$ & $95.3 \%$ & $21.6 \%$ & $0.6 \%$ \\
\hline Users $^{b}$ & $79.2 \%$ & $28.9 \%$ & $33.8 \%$ & $92.1 \%$ & $0.8 \%$ & $39.2 \%$ & $98.0 \%$ \\
\hline \multicolumn{8}{|l|}{ Change } \\
\hline Stoppers ${ }^{c}$ & $2.8 \%$ & $3.8 \%$ & $3.0 \%$ & $1.4 \%$ & $1.8 \%$ & $34.7 \%$ & $1.1 \%$ \\
\hline New users ${ }^{d}$ & $9.5 \%$ & $3.0 \%$ & $15.8 \%$ & $2.0 \%$ & $2.1 \%$ & $4.5 \%$ & $0.3 \%$ \\
\hline
\end{tabular}

Note. ${ }^{a}=$ Participants who did not engage in the behavior neither before nor during the COVID-19 pandemic; ${ }^{b}=$ Participants who engaged in the behavior before and during the COVID-19 pandemic; ${ }^{c}=$ Participants who used to engage in the behavior but withdraw from it during the COVID-19 pandemic; ${ }^{d}=$ Participants who never engaged in the behavior before but started during the COVID-19 pandemic.

\section{Problematic Online Activities During the COVID-19 Pandemic}

Table 3 displays the comparisons between the use of each online activity before and during the COVID-19 pandemic. These analyses were conducted among participants who reported involvement in an online activity both before and during lockdown (i.e., "users"). Given that the prevalence of online gambling was low $(0.8 \% ; n=$ 9 ), this online activity was not considered for further analyses. These results showed that, on average, weekly time in all online activities significantly increased during lockdown $(p<.01)$, with the average increase ranging from 25 minutes (online shopping) to 336 minutes (TV series). This was accompanied by an increased self-reported excessive use for four out of six activities: TV series (12.6\% before lockdown vs. $29.2 \%$ during lockdown), video games $(16.6 \%$ vs. $27 \%)$, instant messaging $(26.8 \%$ vs. $32.7 \%)$, and online sexual activities ( $4.7 \%$ vs. $8.8 \%)$. Interestingly, the proportion of interpersonal problems due to internet use only slightly increased (1.4\% vs. $5.1 \%)$ for online sexual activities and decreased for instant messaging ( $21.1 \%$ vs. $16.7 \%)$ and social networks $(30.4 \%$ vs. 20\%). Self-reported personal impairment increased by $7.6 \%$ for TV series (8.9\% vs. $16.5 \%)$ and $8.6 \%$ for video games ( $8.6 \%$ vs. $17.2 \%$ ) during lockdown. In contrast, self-perceived addictive use of social networks decreased by $3.6 \%(25.6 \%$ vs. $22 \%)$ during lockdown.

Table 4 summarizes the results from the linear regressions predicting changes in internet use (" $\Delta$ time") and problematic use (" $\Delta$ risk") during lockdown. In general, the percentage of variance explained by the resulting models, including predictors of mood states, impulsivity, and lockdown impacts, was low $\left(R^{2}\right.$ between $0.8 \%$ and $3.4 \%)$. 
Table 3. Time per Week and Self-Perceived Severity of Online Activities Among Users Before and During the COVID-19 Pandemic.

\begin{tabular}{|c|c|c|c|c|c|c|c|c|c|c|c|c|c|c|c|}
\hline & \multicolumn{3}{|c|}{ Time per week ( $M$ in minutes, SD) } & \multicolumn{3}{|c|}{ Excessive time investment (\% yes) } & \multicolumn{3}{|c|}{ Interpersonal problems (\% yes) } & \multicolumn{3}{|c|}{ Functional impairment (\% yes) } & \multicolumn{3}{|c|}{$\begin{array}{c}\text { Self-perceived addictive use (\% } \\
\text { yes) }\end{array}$} \\
\hline & $\begin{array}{c}\text { Pre- } \\
\text { lockdown }\end{array}$ & $\begin{array}{l}\text { During } \\
\text { lockdown }\end{array}$ & $\Delta M$ & $\begin{array}{c}\text { Pre- } \\
\text { lockdown }\end{array}$ & $\begin{array}{c}\text { During } \\
\text { lockdown }\end{array}$ & $\Delta \%$ & $\begin{array}{c}\text { Pre- } \\
\text { lockdown }\end{array}$ & $\begin{array}{c}\text { During } \\
\text { lockdown }\end{array}$ & $\Delta \%$ & $\begin{array}{c}\text { Pre- } \\
\text { lockdown }\end{array}$ & $\begin{array}{c}\text { During } \\
\text { lockdown }\end{array}$ & $\Delta \%$ & $\begin{array}{c}\text { Pre- } \\
\text { lockdown }\end{array}$ & $\begin{array}{c}\text { During } \\
\text { lockdown }\end{array}$ & $\Delta \%$ \\
\hline $\begin{array}{l}\text { TV Series } \\
(n=886) \\
\text { Online }\end{array}$ & $\begin{array}{l}365.30 \\
(344.60)\end{array}$ & $\begin{array}{l}701.85 \\
(718.82)\end{array}$ & $+336.50^{* * *}$ & $12.6 \%$ & $29.2 \%$ & $+16.6 \%{ }^{* * *}$ & $15.0 \%$ & $15.5 \%$ & $+0.5 \%$ & $8.9 \%$ & $16.5 \%$ & $+7.6 \%^{* * *}$ & $6.7 \%$ & $7.0 \%$ & $+0.3 \%$ \\
\hline $\begin{array}{l}\text { Sexual } \\
\text { activities } \\
(n=323)\end{array}$ & $\begin{array}{c}64.59 \\
(78.53)\end{array}$ & $\begin{array}{c}112.97 \\
(250.00)\end{array}$ & $+48.38^{* * *}$ & $4.7 \%$ & $8.8 \%$ & $+4.1 \%{ }^{* *}$ & $1.4 \%$ & $5.1 \%$ & $+3.7 \%{ }^{*}$ & $2.4 \%$ & $3.4 \%$ & $+1.0 \%$ & $6.8 \%$ & $4.4 \%$ & $-2.4 \%$ \\
\hline $\begin{array}{l}\text { Video } \\
\text { games } \\
(n=378)\end{array}$ & $\begin{array}{l}376.74 \\
(500.15)\end{array}$ & $\begin{array}{c}644.75 \\
(780.43)\end{array}$ & $+268.01^{* \star *}$ & $16.6 \%$ & $27.0 \%$ & $+10.4 \%^{* * *}$ & $26.7 \%$ & $19.6 \%$ & $-7.1 \%{ }^{* *}$ & $8.6 \%$ & $17.2 \%$ & $+8.6 \%^{* * *}$ & $11.0 \%$ & $7.7 \%$ & $-3.3 \%$ \\
\hline $\begin{array}{l}\text { Social } \\
\text { networks } \\
(n=1,030)\end{array}$ & $\begin{array}{c}708.44 \\
(826.27)\end{array}$ & $\begin{array}{l}853.73 \\
(957.88)\end{array}$ & $+145.29^{* * *}$ & $46.4 \%$ & $46.3 \%$ & $-0.1 \%$ & $30.4 \%$ & $20.0 \%$ & $-10.4 \%^{* * *}$ & $20.3 \%$ & $18.1 \%$ & $-2.2 \%$ & $25.6 \%$ & $22.0 \%$ & $-3.6 \%{ }^{* *}$ \\
\hline $\begin{array}{l}\text { Online } \\
\text { shopping } \\
(n=438)\end{array}$ & $\begin{array}{l}52.30 \\
(75.20)\end{array}$ & $\begin{array}{c}77.92 \\
(154.92)\end{array}$ & $+25.62^{* * *}$ & $4.0 \%$ & $6.6 \%$ & +2.6 & $11.1 \%$ & $8.6 \%$ & $-2.5 \%$ & $2.8 \%$ & $3.3 \%$ & $+0.5 \%$ & $4.8 \%$ & $3.5 \%$ & $-1.3 \%$ \\
\hline $\begin{array}{l}\text { Instant } \\
\text { messaging } \\
(n=1,096)\end{array}$ & $\begin{array}{c}643.01 \\
(805.15)\end{array}$ & $\begin{array}{c}796.68 \\
(940.42)\end{array}$ & $+153.67^{* * \star}$ & $26.8 \%$ & $32.7 \%$ & $+5.9^{* \star *}$ & $21.1 \%$ & $16.7 \%$ & $-4.4 \%{ }^{* *}$ & $14.9 \%$ & $12.8 \%$ & $-2.1 \%$ & $14.7 \%$ & $16.0 \%$ & $+1.3 \%$ \\
\hline
\end{tabular}


Table 4. Linear Regressions Predicting Changes in Time per Week and Problematic Engagement in Online Activities Before and During the COVID-19 Pandemic.

\begin{tabular}{|c|c|c|c|c|c|c|c|c|c|c|c|c|}
\hline & \multicolumn{2}{|c|}{$\begin{array}{c}\text { TV Series } \\
(n=886)\end{array}$} & \multicolumn{2}{|c|}{ Online Sexual activities ( $n=323$ ) } & \multicolumn{2}{|c|}{$\begin{array}{l}\text { Video games } \\
(n=378)\end{array}$} & \multicolumn{2}{|c|}{$\begin{array}{c}\text { Social networks } \\
\quad(n=1,030)\end{array}$} & \multicolumn{2}{|c|}{$\begin{array}{c}\text { Online shopping } \\
(n=438)\end{array}$} & \multicolumn{2}{|c|}{$\begin{array}{l}\text { Instant messaging } \\
\qquad(n=1,096)\end{array}$} \\
\hline & $\begin{array}{c}\Delta \text { time }^{\text {a }} \\
\beta\end{array}$ & $\begin{array}{c}\Delta \text { risk }^{\mathrm{b}} \\
\beta \\
\end{array}$ & $\begin{array}{c}\Delta \text { time }^{\text {a }} \\
\beta\end{array}$ & $\begin{array}{c}\Delta \text { risk }^{\mathrm{b}} \\
\beta\end{array}$ & $\begin{array}{c}\Delta \text { time }^{\text {a }} \\
\beta \\
\end{array}$ & $\begin{array}{c}\Delta \text { risk }^{\mathrm{b}} \\
\beta\end{array}$ & $\begin{array}{c}\Delta \text { time }^{\text {a }} \\
\beta\end{array}$ & $\begin{array}{c}\Delta \text { risk }^{\mathrm{b}} \\
\beta\end{array}$ & $\begin{array}{c}\Delta \text { time }^{\text {a }} \\
\beta\end{array}$ & $\begin{array}{c}\Delta \text { risk }^{\mathrm{b}} \\
\beta\end{array}$ & $\begin{array}{c}\Delta \text { time }^{\text {a }} \\
\beta\end{array}$ & $\begin{array}{c}\Delta \text { risk }^{\mathrm{b}} \\
\beta\end{array}$ \\
\hline Gender (female) & - & - & - & - & - & - & $0.10^{* *}$ & - & - & - & - & - \\
\hline Age & - & - & - & - & - & - & - & $0.08^{*}$ & - & $0.12^{*}$ & - & - \\
\hline \multicolumn{13}{|l|}{ Lockdown impact } \\
\hline Mental health & - & $0.16^{* * *}$ & - & $0.13^{*}$ & - & - & - & - & - & $0.16^{* *}$ & - & - \\
\hline Personal finances & - & $0.07^{*}$ & - & - & - & $0.11^{*}$ & - & - & - & - & - & - \\
\hline Relationships quality & - & - & - & - & - & - & - & - & - & - & - & - \\
\hline \multicolumn{13}{|l|}{ PANAS } \\
\hline Positive affect & $-0.09^{*}$ & - & - & - & - & - & - & $-0.08^{*}$ & - & - & - & $-0.10^{* *}$ \\
\hline Negative affect & - & - & - & - & - & - & - & - & $0.15^{*}$ & - & - & - \\
\hline \multicolumn{13}{|l|}{ s-UPPS-P } \\
\hline Negative urgency & - & - & - & - & - & - & - & - & - & - & - & - \\
\hline Lack of premeditation & - & - & - & - & - & - & - & - & - & - & - & - \\
\hline Lack of perseverance & - & - & - & - & - & - & $0.07^{*}$ & - & - & - & - & $0.07^{*}$ \\
\hline Sensation seeking & - & - & - & $-0.12^{*}$ & - & - & - & - & - & - & - & - \\
\hline \multicolumn{13}{|l|}{ Model fit } \\
\hline$F$ & $5.75^{*}$ & $13.18^{* \star *}$ & - & $4.72^{* *}$ & - & $4.13^{*}$ & $6.20^{* *}$ & $4.90^{\star *}$ & $6.20^{*}$ & $5.87^{* *}$ & - & $5.27^{* *}$ \\
\hline$R^{2}$ & $0.8 \%$ & $3.4 \%$ & - & $3.4 \%$ & - & $1.3 \%$ & $1.5 \% \%$ & $1.1 \%$ & $2.1 \%$ & $3.1 \%$ & - & $1.1 \%$ \\
\hline
\end{tabular}



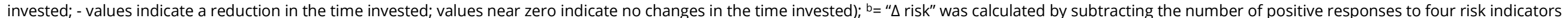



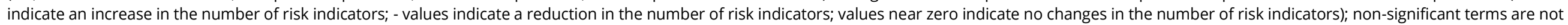
included in the table (-) to facilitate its interpretation. 


\section{Discussion}

The COVID-19 pandemic has led to large-scale changes in internet use as the global population adjusts to changing conditions in work and study, recreation, and socializing opportunities. This study aimed to examine users' engagement in different online activities during the mandatory lockdown in Spain, analyzing whether increased use was associated with increased prevalence of problematic use and the extent to which two psychological factors (i.e., negative mood states and trait impulsivity), were predictive of greater risk of problematic use during lockdown.

Contrary to our expectations, the lockdown context did not greatly change the proportion of users of different online activities. Between 60.8\%-98.6\% remained "users" or "non-users" of the targeted online activities (i.e., did not show changes in their engagement pattern during the COVID-19 pandemic) and only a small proportion started or stopped engaging in these online activities. The two online activities with the highest proportion of new users were watching online TV series (9.5\% of new users) and playing online video games (15.8\%), which are activities known to have specific hedonic motives (Flayelle et al., 2020; Khang et al., 2013), thus supporting the hypothesis that people engaged in these activities to deal with boredom, frustration, and monotony during lockdown. Between $1.1 \%$ and $34.7 \%$ of participants stopped using certain online activities during lockdown. Online shoppers had the highest proportion of "stoppers", which may be due to practical aspects (i.e., the cessation of delivery services during lockdown) or economic reasons (individuals experiencing or anticipating financial problems or uncertainty). It is less clear why some participants stopped using other online activities. Some possible reasons include accessibility problems due to potential digital inequalities that arose in lockdown (Beaunoyer et al., 2020) or having less free leisure time due to greater responsibilities (e.g., increased child-rearing time). Given its relevance for understanding ICT use in the current pandemic situation and in potential future situations of lockdown, determining motives behind starting to use versus stop using specific online services warrants further research.

Our findings support general observations on pandemic-related internet use, as our participants reported a large increase in their total internet use during lockdown. The online activities with the largest increase were watching TV series (mean increase of 5.6 hours per week) and playing video games (mean increase of 4.5 hours per week). Increased use was also observed among activities that facilitate social contact: i.e., instant messaging (2.6 hours) and social networks (2.4 hours). These findings align with self-determination theory (Rigby \& Ryan, 2017), which proposes that entertainment media satisfy basic psychological needs of relatedness, autonomy, and competence. In the context of lockdown, individuals may increase activities such as their TV series viewing and video games use as a way to deal with the boredom and monotony derived from the lack of real-life stimulating experiences. Similarly, they may turn to gaming, social networks, or instant messaging to compensate for social isolation and loneliness. In line with this hypothesis, we observed that the increase in time spent online in activities fulfilling needs that are not directly affected by lockdown (e.g., sexual needs in the case of online sexual activities) was more limited. These results are consistent with those of recent studies showing that social compensation via gaming (i.e., the use of video games to remain in contact with friends) or watching TV series for emotional enhancement (i.e., experiencing positive emotions) or enrichment (i.e., developing one's intellectual experiences and knowledge) predict the level of engagement in these online activities during the COVID-19 pandemic (Boursier et al., 2021; Giardina et al., 2021). Yet, the studies by Boursier et al. (2021) or Giardina et al. (2021) also showed that gaming or watching TV series as a way to escape from negative emotional states (i.e., escapism motives) is susceptible to foster over-involvement in those online activities and may be associated with increased emotional distress. Similarly, perceived feelings of loneliness during COVID-19 lockdown are related to increased odds of excessive social media use that and associated with heightened anxiety (Boursier et al., 2020). In the lockdown context, forced isolation may increase the sense of loneliness and promote the use of social networks or instant messaging to compensate for the lack of face-to-face interaction. As past research linked social media overuse with poorer relationships quality and increased feelings of loneliness (Kim et al., 2009), it cannot be excluded that at risk individuals, in a lockdown context, might be prone to intensify their involvement in online activities to a point where it become dysfunctional. Therefore, future research is needed to determine whether this increase in time devoted to online activities is associated with a growth in the prevalence of functionally impairing online behaviors, i.e., uncontrolled behaviors having tangible negative consequences. 
High involvement in an online activity is not inherently nor necessarily problematic (Billieux et al., 2015; Leung, 2007). Consistent with this view, this study shows that increased internet use during lockdown was not accompanied by a proportional growth in problematic use for most online activities (except for problematic TV series watching and video games use). Furthermore, the proportion of participants experiencing interpersonal problems due to their involvement in online activities actually decreased during lockdown. This would be applicable to online activities such as social network sites (interpersonal problems reduced by $10.4 \%$ ), online video games (reduced by $7.1 \%$ ) or instant messaging applications (reduced by $4.4 \%$ ). Similarly, the proportion of participants reporting that their use of social networks was addictive decreased by $3.6 \%$ during the COVID-19 pandemic. This reduction in the risk associated to different online activities could be due to the fact that, during lockdown, such activities (typically social media use or instant messaging) enable to socialize and remain connected with family and/or friends, and therefore, mitigate feelings of loneliness. At the same time, the perception of "interference" due to ICT (over)use may have changed during lockdown: while spending a large amount of time online may notably interfere in the pre-pandemic context (e.g., because it generates conflicts with family/friends or negatively impact upon job or academic duties), it might not have been the case in the pandemic context.

In contrast, we observed a significant increase in the proportion of participants who considered that they spent too much time watching TV series or playing video games ( $16.6 \%$ and $10.4 \%$ respectively), as well as reporting functional impairment due to these activities (7.6\% and $8.6 \%$ ). Based on current views of the negative outcomes associated with these behaviors (Flayelle et al., 2020; King \& Delfabbro, 2018), it is possible that increased time in these activities had a detrimental effect on job or academic productivity. Therefore, even when the general trend did not indicate a significant growth in the risk of problematic involvement in online activities during the COVID19 pandemic, we believe that consensus guidelines (e.g., Király et al., 2020) might be useful, at least in the short term, in order to minimize the risk of experiencing problems derived due to excessive involvement in particular online activities (such as watching TV series or playing video games). Yet, such guidelines should also recognize that healthy and controlled involvement in online activities is an adaptive coping strategy to face adversity and fulfil basic needs (e.g., social contact, autonomy) in a pandemic-related lockdown context. In the long term, we cannot rule out the possibility that the prevention of problematic use of online activities will probably require more active measures (e.g., community initiatives to promote social bonds), especially when it comes to restoring normal ICT use patterns after the pandemic.

Affect and impulsivity were found to have a limited association with the main variables in this study. This suggests that established risk factors for problematic internet use may not necessarily apply to the same degree in the context of the pandemic (i.e., when larger changes to personal circumstances become more salient). Positive affect was a protective factor for different indicators of problematic use of online activities, whereas negative affect predicted an increased risk related to certain online activities. Similarly, the negative impact of lockdown on mental health and/or personal finances increased the risk of problematic internet use. These findings are consistent with the compensatory internet use theory (Kardefelt-Winther, 2014), which proposes that internet use and misuse may be explained by the need to compensate for real-life negative situations. This is applicable to individuals under lockdown who tend to experience boredom and other negative affect (Brooks et al., 2020). Only the impulsivity domains of lack of perseverance (risk factor) and sensation seeking (protective factor) were associated with internet use in this study. These impulsivity domains are typically secondary for predicting problematic online activity (Wéry et al., 2018) and other behavioral problems (Berg et al., 2015), thereby reiterating that some risk factors may not necessarily apply in the usual way under lockdown conditions.

\section{Limitations}

Despite its novel findings, this study is not without limitations. First, the engagement in online activities before the COVID-19 pandemic was assessed retrospectively, which may be influenced by recall biases and stress as well as pandemic-related stress and uncertainties (Solhan et al., 2009). Second, we asked participants to self-report the time they spent online, which is an approach prone to measurement inaccuracies (Grondin, 2010). The sample was self-selected which may have been biased toward higher functioning individuals whose internet use was more regulated than those who would not respond to an unpaid survey. Besides, problematic involvement in online activities was assessed with a set of dichotomous custom-made items rather than psychometrically validated instruments. This choice resulted from the need to have a brief and consistent screening approach focused on 
key indicators (e.g., functional impairment, perceived addictive use) for all target behaviors. However, the use of a dichotomous answer scale rather than a continuous -i.e., Likert- response format may have hindered the identification of participants with different degrees of severity and impairment related to their internet use. Finally, in this study we did not measure other psychosocial variables that might been useful to understand ICT use during lockdown (such as perceived loneliness, social support, or work conditions). Similarly, as our survey gathered basic detail about each activity, it did not enable fine-grained comparisons within different types of Internet use. This was the case of the exploration of online sexual activities beyond pornography use (e.g., the use of chat or webcams for sexual purposes). In light of these issues, this work should be considered preliminary and in need of replication, particularly in a representative sample, and using alternative methods of data collection, such as interviews, to verify experiences.

\section{Conclusions}

The present research provided original data on psychological issues arising from the pandemic-related lockdown in Spain, which has been one of the most negatively affected European countries. These results suggest that increased time spent in online activities during the lockdown was not related to a proportional increase in problematic usage patterns, except for some indicators of problematic TV series watching and video games use. These findings have implications for considering the relationship between general internet usage and problem use, and suggest that, for many individuals, these behavioral changes may constitute adaptive coping strategies in the context of the pandemic. To the best of our knowledge, this is the first study providing evidence for changes in the usage pattern of multiple online activities during the COVID-19 pandemic. The majority of studies conducted so far are focused on a single online activity (e.g., social media use [Boursier et al., 2020], video games [Giardina et al., 2021], or TV series [Boursier et al., 2021]), rather than exploring the plurality of available online activities simultaneously; despite previous literature indicates that excessive and problematic online activities are interconnected at multiple levels (Baggio et al., 2018; Castro-Calvo et al., 2018). Therefore, addressing the impact of COVID-19 pandemic conjointly on most popular online activities constitutes an important contribution of this research. Furthermore, this empirical study is also one of the few assessing online activity during the COVID-19 pandemic in Spain (which is among the most affected European countries and, therefore, a relevant country to focus on). Finally, our findings convey a rather positive message, which is that, for most individuals, online activities generally represent adaptive coping to face the stress derived from the COVID-19 pandemic and/or to maintain social bounds. This central finding of our study is at odds with some recent claims in the media about the dangers of ICT in the current pandemic context (in relation to the development of unhealthy or addictive usage patterns).

\section{References}

Abel, T., \& McQueen, D. (2020). The COVID-19 pandemic calls for spatial distancing and social closeness: Not for social distancing! International Journal of Public Health, 65(3), 231-231. https://doi.org/10.1007/s00038-020-013667

Albertella, L., Rotaru, K., Christensen, E., Lowe, A., Brierley, M.-E., Richardson, K., Chamberlain, S. R., Lee, R. S. C., Kayayan, E., Grant, J. E., Schluter-Hughes, S., Ince, C., Fontenelle, L. F., Segrave, R., \& Yücel, M. (2021). The influence of trait compulsivity and impulsivity on addictive and compulsive behaviors during COVID-19. Frontiers in Psychiatry, 12, Article 634583. https://doi.org/10.3389/fpsyt.2021.634583

Baggio, S., Starcevic, V., Studer, J., Simon, O., Gainsbury, S. M., Gmel, G., \& Billieux, J. (2018). Technology-mediated addictive behaviors constitute a spectrum of related yet distinct conditions: A network perspective. Psychology of Addictive Behaviors, 32(5), 564-572. https://doi.org/10.1037/adb0000379

Beaunoyer, E., Dupéré, S., \& Guitton, M. J. (2020). COVID-19 and digital inequalities: Reciprocal impacts and mitigation strategies. Computers in Human Behavior, 111, Article 106424.

https://doi.org/10.1016/j.chb.2020.106424

Berg, J. M., Latzman, R. D., Bliwise, N. G., \& Lilienfeld, S. O. (2015). Parsing the heterogeneity of impulsivity: A meta-analytic review of the behavioral implications of the UPPS for psychopathology. Psychological Assessment, 27(4), 1129-1146. https://doi.org/10.1037/pas0000111 
Billieux, J., Flayelle, M., Rumpf, H.-J., \& Stein, D. J. (2019). High involvement versus pathological involvement in video games: A crucial distinction for ensuring the validity and utility of gaming disorder. Current Addiction Reports, 6(3), 323-330. https://doi.org/10.1007/s40429-019-00259-x

Billieux, J., Schimmenti, A., Khazaal, Y., Maurage, P., \& Heeren, A. (2015). Are we overpathologizing everyday life? A tenable blueprint for behavioral addiction research. Journal of Behavioral Addictions, 4(3), 119-123.

https://doi.org/10.1556/2006.4.2015.009

Billieux, J., \& Van Der Linden, M. (2012). Problematic use of the internet and self-regulation: A review of the initial studies. The Open Addiction Journal, 5, 24-29. https://doi.org/10.2174/1874941001205010024

Boursier, V., Gioia, F., Musetti, A., \& Schimmenti, A. (2020). Facing loneliness and anxiety during the COVID-19 isolation: The role of excessive social media use in a sample of Italian adults. Frontiers in Psychiatry, 11, Article 586222. https://doi.org/10.3389/fpsyt.2020.586222

Boursier, V., Musetti, A., Gioia, F., Flayelle, M., Billieux, J., \& Schimmenti, A. (2021). Is watching TV series an adaptive coping strategy during the COVID-19 pandemic? Insights from an Italian community sample. Frontiers in Psychiatry, 12, Article 599859. https://doi.org/10.3389/fpsyt.2021.599859

Brand, M., Wegmann, E., Stark, R., Müller, A., Wölfling, K., Robbins, T. W., \& Potenza, M. N. (2019). The Interaction of Person-Affect-Cognition-Execution (I-PACE) model for addictive behaviors: Update, generalization to addictive behaviors beyond internet-use disorders, and specification of the process character of addictive behaviors. Neuroscience \& Biobehavioral Reviews, 104, 1-10. https://doi.org/10.1016/j.neubiorev.2019.06.032

Brooks, S. K., Webster, R. K., Smith, L. E., Woodland, L., Wessely, S., Greenberg, N., \& Rubin, G. J. (2020). The psychological impact of quarantine and how to reduce it: rapid review of the evidence. The Lancet, 395(10227), 912-920. https://doi.org/10.1016/S0140-6736(20)30460-8

Cándido, A., Orduña, E., Perales, J. C., Verdejo-García, A., \& Billieux, J. (2012). Validation of a short Spanish version of the UPPS-P impulsive behaviour scale. Trastornos Adictivos, 14(3), 73-78. https://doi.org/10.1016/S15750973(12)70048-X

Fineberg, N. A., Demetrovics, Z., Stein, D. J., Ioannidis, K., Potenza, M. N., Grünblatt, E., Brand, M., Billieux, J., Carmi, L., King, D. L., Grant, J. E., Yücel, M., Dell'Osso, B., Rumpf, H. J., Hall, N., Hollander, E., Goudriaan, A., Menchon, J., Zohar, J., ... Chamberlain, S. R. (2018). Manifesto for a European research network into Problematic Usage of the Internet. European Neuropsychopharmacology, 28(11), 1232-1246.

https://doi.org/10.1016/j.euroneuro.2018.08.004

Flayelle, M., Maurage, P., Di Lorenzo, K. R., Vögele, C., Gainsbury, S. M., \& Billieux, J. (2020). Binge-watching: What do we know so far? A first systematic review of the evidence. Current Addiction Reports, 7(1), 44-60.

https://doi.org/https://doi.org/10.1007/s40429-020-00299-8

Gecaite-Stonciene, J., Saudargiene, A., Pranckeviciene, A., Liaugaudaite, V., Griskova-Bulanova, I., Simkute, D., Naginiene, R., Dainauskas, L. L., Ceidaite, G., \& Burkauskas, J. (2021). Impulsivity mediates associations between problematic internet use, anxiety, and depressive symptoms in students: A cross-sectional COVID-19 study. Frontiers in Psychiatry, 12, Article 634464. https://doi.org/10.3389/fpsyt.2021.634464

Giardina, A., Di Blasi, M., Schimmenti, A., King, D. L., Starcevic, V., \& Billieux, J. (2021). Online gaming and prolonged self-isolation: Evidence from Italian gamers during the COVID-19 outbreak. Clinical Neuropsychiatry, 18(1), 65-74. https://doi.org/10.36131/cnfioritieditore20210106

Grondin, S. (2010). Timing and time perception: A review of recent behavioral and neuroscience findings and theoretical directions. Attention, Perception, \& Psychophysics, 72(3), 561-582. https://doi.org/10.3758/APP.72.3.561 
Hale, T., Angrist, N., Goldszmidt, R., Kira, B., Petherick, A., Phillips, T., Webster, S., Cameron-Blake, E., Hallas, L., Majumdar, S., \& Tatlow, H. (2021). A global panel database of pandemic policies (Oxford COVID-19 Government Response Tracker). Nature Human Behaviour, 5, 529-538. https://doi.org/10.1038/s41562-021-01079-8

Hunsley, J., \& Mash, E. J. (2008). A guide to assessments that work. Oxford University Press.

Kardefelt-Winther, D. (2014). A conceptual and methodological critique of internet addiction research: Towards a model of compensatory internet use. Computers in Human Behavior, 31, 351-354.

https://doi.org/10.1016/j.chb.2013.10.059

Kardefelt-Winther, D., Heeren, A., Schimmenti, A., van Rooij, A., Maurage, P., Carras, M., Edman, J., Blaszczynski, A., Khazaal, Y., \& Billieux, J. (2017). How can we conceptualize behavioural addiction without pathologizing common behaviours? Addiction, 112(10), 1709-1715. https://doi.org/10.1111/add.13763

Khang, H., Kim, J. K., \& Kim, Y. (2013). Self-traits and motivations as antecedents of digital media flow and addiction: The Internet, mobile phones, and video games. Computers in Human Behavior, 29(6), 2416-2424. https://doi.org/10.1016/J.CHB.2013.05.027

Kim, J., Larose, R., \& Peng, W. (2009). Loneliness as the cause and the effect of problematic Internet use: The relationship between Internet use and psychological well-being. CyberPsychology \& Behavior, 12(4), 451-455. https://doi.org/10.1089/cpb.2008.0327

King, D. L., \& Delfabbro, P. (2018). The concept of "harm" in Internet gaming disorder. Journal of Behavioral Addictions, 7(3), 562-564. https://doi.org/10.1556/2006.7.2018.24

King, D. L., Delfabbro, P. H., Billieux, J., \& Potenza, M. N. (2020). Problematic online gaming and the COVID-19 pandemic. Journal of Behavioral Addiction, 9(2), 184-186. https://doi.org/10.1556/2006.2020.00016

Király, O., Potenza, M. N., Stein, D. J., King, D. L., Hodgins, D. C., Saunders, J. B., Griffiths, M. D., Gjoneska, B., Billieux, J., Brand, M., Abbott, M. W., Chamberlain, S. R., Corazza, O., Burkauskas, J., Sales, C. M. D., Montag, C., Lochner, C., Grünblatt, E., Wegmann, E., ... Demetrovics, Z. (2020). Preventing problematic internet use during the COVID-19 pandemic: Consensus guidance. Comprehensive Psychiatry, 100, Article 152180.

https://doi.org/10.1016/j.comppsych.2020.152180

Leung, L. (2007). Stressful life events, motives for internet use, and social support among digital kids. CyberPsychology \& Behavior, 10(2), 204-214. https://doi.org/10.1089/cpb.2006.9967

MacLaren, V. V., Fugelsang, J. A., Harrigan, K. A., \& Dixon, M. J. (2011). The personality of pathological gamblers: A meta-analysis. Clinical Psychology Review, 31(6), 1057-1067. https://doi.org/10.1016/j.cpr.2011.02.002

Mestre-Bach, G., Blycker, G. R., \& Potenza, M. N. (2020). Pornography use in the setting of the COVID-19 pandemic. Journal of Behavioral Addictions, 9(2), 181-183. https://doi.org/10.1556/2006.2020.00015

Montag, C., Wegmann, E., Sariyska, R., Demetrovics, Z., \& Brand, M. (2019). How to overcome taxonomical problems in the study of Internet use disorders and what to do with "smartphone addiction"? Journal of Behavioral Addictions, 9(4), 908-914. https://doi.org/10.1556/2006.8.2019.59

O'Brien, R. M. (2007). A caution regarding rules of thumb for variance inflation factors. Quality \& Quantity, 41(5), 673-690. https://doi.org/10.1007/s11135-006-9018-6

Ornell, F., Schuch, J. B., Sordi, A. O., \& Kessler, F. H. P. (2020). "Pandemic fear" and COVID-19: Mental health burden and strategies. Revista Brasileira de Psiquiatria, 42(3), 232-235. https://doi.org/10.1590/1516-4446-20200008 
Ostinelli, E. G., Zangani, C., Giordano, B., Maestri, D., Gambini, O., D’Agostino, A., Furukawa, T. A., \& Purgato, M. (2021). Depressive symptoms and depression in individuals with internet gaming disorder: A systematic review and meta-analysis. Journal of Affective Disorders, 284, 136-142. https://doi.org/10.1016/j.jad.2021.02.014

Rigby, C. S., \& Ryan, R. M. (2017). Time well-spent? Motivation for entertainment media and its eudaimonic aspects through the lens of self-determination theory. In L. Reinecke \& M. B. Oliver (Eds.), The Routledge handbook of media use and well-being: International perspectives on theory and research on positive media effects (pp. 34-48). Routledge. https://doi.org/10.4324/9781315714752

Sandín, B., Chorot, P., Lostao, L., Joiner, T. E., Santed, M. A., \& Valiente, R. M. (1999). Escalas PANAS de afecto positivo y negativo: Validacion factorial y convergencia transcultural. In Psicothema (Vol. 11, Issue 1, pp. 37-51).

Sandín, B., Valiente, R. M., García-Escalera, J., \& Chorot, P. (2020). Psychological impact of the COVID-19 pandemic: Negative and positive effects in Spanish people during the mandatory national quarantine. Revista de Psicopatología y Psicología Clínica, 25(1), 1-22. https://doi.org/10.5944/rppc.27569

Schimmenti, A., Billieux, J., \& Starcevic, V. (2020). The four horsemen of fear: An integrated model of understanding fear experiences during the COVID-19 pandemic. Clinical Neuropsychiatry, 17(2), 41-45.

Sharman, S., Roberts, A., Bowden-Jones, H., \& Strang, J. (2021). Gambling in COVID-19 lockdown in the UK: Depression, stress, and anxiety. Frontiers in Psychiatry, 12, Article 621497.

https://doi.org/10.3389/fpsyt.2021.621497

Shigemura, J., Ursano, R. J., Morganstein, J. C., Kurosawa, M., \& Benedek, D. M. (2020). Public responses to the novel 2019 coronavirus (2019-nCoV) in Japan: Mental health consequences and target populations. Psychiatry and Clinical Neurosciences, 74(4), 281-282. https://doi.org/10.1111/pcn.12988

Solhan, M. B., Trull, T. J., Jahng, S., \& Wood, P. K. (2009). Clinical assessment of affective instability: Comparing EMA indices, questionnaire reports, and retrospective recall. Psychological Assessment, 21(3), 425-436. https://doi.org/10.1037/a0016869

Starcevic, V., \& Aboujaoude, E. (2017). Internet addiction: Reappraisal of an increasingly inadequate concept. CNS Spectrums, 22(1), 7-13. https://doi.org/10.1017/S1092852915000863

Teng, Z., Pontes, H. M., Nie, Q., Griffiths, M. D., \& Guo, C. (2021). Depression and anxiety symptoms associated with internet gaming disorder before and during the COVID-19 pandemic: A longitudinal study. Journal of Behavioral Addictions, 10(1), 169-180. https://doi.org/10.1556/2006.2021.00016

UNICEF. (2020). Coronavirus disease (COVID-19) and its implications for protecting children online. https://www.unicef.org/documents/covid-19-and-implications-protecting-children-online

Velotti, P., Rogier, G., Beomonte Zobel, S., \& Billieux, J. (2021). Association between gambling disorder and emotion (dys)regulation: A systematic review and meta-analysis. Clinical Psychology Review, 87, Article 102037. https://doi.org/10.1016/j.cpr.2021.102037

Wang, C., Pan, R., Wan, X., Tan, Y., Xu, L., Ho, C. S., \& Ho, R. C. (2020). Immediate psychological responses and associated factors during the initial stage of the 2019 coronavirus disease (COVID-19) epidemic among the general population in China. International Journal of Environmental Research and Public Health, 17(5), Article 1729. https://doi.org/10.3390/ijerph17051729

Wéry, A., Deleuze, J., Canale, N., \& Billieux, J. (2018). Emotionally laden impulsivity interacts with affect in predicting addictive use of online sexual activity in men. Comprehensive Psychiatry, 80, 192-201.

https://doi.org/10.1016/j.comppsych.2017.10.004 
Wiederhold, B. K. (2020). Social media use during social distancing. Cyberpsychology, Behavior and Social Networking, 23(5), 275-276. https://doi.org/10.1089/cyber.2020.29181.bkw

World Health Organization. (2020a). Excessive screen use and gaming considerations during \#COVID19. http://www.emro.who.int/mnh/news/considerations-for-young-people-on-excessive-screen-use-duringcovid19.html

World Health Organization. (2020b). WHO Director-General's opening remarks at the media briefing on COVID-19 11 March 2020. https://www.who.int/dg/speeches/detail/who-director-general-s-opening-remarks-at-the-mediabriefing-on-covid-19---11-march-2020

\section{Supplementary Material}

Table S1. Participants' Characteristics According to Each Profile (TV Series).

\begin{tabular}{|c|c|c|c|c|c|}
\hline & \multicolumn{5}{|c|}{ TV Series } \\
\hline & $\begin{array}{l}\text { Non-users } \\
M(S D) \text { or } \%\end{array}$ & $\begin{array}{c}\text { Users } \\
M(S D) \text { or } \%\end{array}$ & $\begin{array}{c}\text { Stopper } \\
M(S D) \text { or } \%\end{array}$ & $\begin{array}{l}\text { New users } \\
M(S D) \text { or } \%\end{array}$ & Inferential statistic \\
\hline \multicolumn{6}{|l|}{ Gender } \\
\hline Male & $11.6 \%$ & $74.7 \%$ & $3.6 \%$ & $10.2 \%$ & \multirow{2}{*}{$\chi^{2}=8.85^{*}$} \\
\hline Female & $7 \%$ & $81.5 \%$ & $2.4 \%$ & $9.1 \%$ & \\
\hline Age & $31.39(12.72)^{b, d}$ & $25.59(8.90)^{a}$ & $28.35(11.32)$ & $27.63(11.27)^{a}$ & $F=11.67^{* \star *}$ \\
\hline \multicolumn{6}{|l|}{ Lockdown impact } \\
\hline Mental health & $4.46(2.46)^{b}$ & $5.33(2.39)^{a}$ & $4.74(2.55)$ & $4.84(2.44)$ & $F=4.96^{* *}$ \\
\hline Personal finances & $4.16(3.07)$ & $4.51(3.07)$ & $3.94(3.17)$ & $4.15(2.94)$ & $F=0.99$ \\
\hline Relationships quality & $3.61(2.75)$ & $4.00(2.59)$ & $4.35(2.91)$ & $3.89(2.55)$ & $F=0.90$ \\
\hline \multicolumn{6}{|l|}{ PANAS } \\
\hline Positive affect & $27.77(8.04)^{b}$ & $24.71(7.53)^{a}$ & $27.25(8.83)$ & $25.71(8.53)$ & $F=4.94^{* *}$ \\
\hline Negative affect & $21.47(7.70)$ & $22.61(7.52)$ & $24.32(8.45)$ & $22.45(7.38)$ & $F=1.11$ \\
\hline \multicolumn{6}{|l|}{ S-UPPS-P } \\
\hline Negative urgency & $8.66(3.17)^{b}$ & $9.72(2.82)^{\mathrm{a}}$ & $9.46(3.15)$ & $9.22(2.95)$ & $F=3.94^{* *}$ \\
\hline Lack of premeditation & $7.36(2.77)$ & $7.78(2.28)$ & $7.64(1.94)$ & $7.62(2.05)$ & $F=0.93$ \\
\hline Lack of perseverance & $7.40(2.51)$ & 7.61 (2.39) & $7.96(2.56)$ & $7.38(2.32)$ & $F=0.61$ \\
\hline Sensation seeking & $8.61(2.85)$ & $9.36(2.80)$ & $8.92(2.98)$ & $9.11(2.98)$ & $F=2.09$ \\
\hline
\end{tabular}

Note. ${ }^{*} p<.05,{ }^{* *} p<.01,{ }^{* * *} p<.001 ;{ }^{\mathrm{a}}=$ Statistically significant in comparison to non-users; ${ }^{\mathrm{b}}=$ Statistically significant in comparison to users; $c=$ Statistically significant in comparison to stoppers; $d=$ Statistically significant in comparison to new user. 


\begin{tabular}{|c|c|c|c|c|c|}
\hline & \multicolumn{5}{|c|}{ Online sexual activities } \\
\hline & $\begin{array}{l}\text { Non-users } \\
M(S D) \text { or } \%\end{array}$ & $\begin{array}{c}\text { Users } \\
M(S D) \text { or } \%\end{array}$ & $\begin{array}{c}\text { Stopper } \\
M(S D) \text { or } \%\end{array}$ & $\begin{array}{l}\text { New users } \\
M(S D) \text { or } \%\end{array}$ & Inferential statistic \\
\hline \multicolumn{6}{|l|}{ Gender } \\
\hline Male & $30.9 \%$ & $59.8 \%$ & $6.6 \%$ & $2.8 \%$ & \multirow{2}{*}{$\chi^{2}=282.88^{* * *}$} \\
\hline Female & $80.4 \%$ & $14 \%$ & $2.4 \%$ & $3.2 \%$ & \\
\hline Age & $27.66(10.75)^{b}$ & $23.67(6.24)^{a}$ & $26.76(10.17)$ & $23.71(8.23)$ & $F=13.77^{* * *}$ \\
\hline \multicolumn{6}{|l|}{ Lockdown impact } \\
\hline Mental health & $5.32(2.40)$ & $4.90(2.42)$ & $4.69(2.33)$ & $5.91(2.75)$ & $F=3.79^{*}$ \\
\hline Personal finances & $4.61(3.07)^{b}$ & $4.05(2.96)^{a}$ & $4.02(3.33)$ & $4.65(3.29)$ & $F=2.80^{*}$ \\
\hline Relationships quality & $3.93(2.58)$ & $4.09(2.68)$ & $3.93(2.51)$ & $3.59(2.67)$ & $F=0.52$ \\
\hline \multicolumn{6}{|l|}{ PANAS } \\
\hline Positive affect & $25.42(7.83)$ & $24.75(7.70)$ & $24.94(8.29)$ & $23.44(6.32)$ & $F=0.97$ \\
\hline Negative affect & $22.70(7.41)^{d}$ & $21.73(7.15)^{d}$ & $22.48(9.52)$ & $27.10(9.75)^{a, b}$ & $F=4.76^{\star *}$ \\
\hline \multicolumn{6}{|l|}{ S-UPPS-P } \\
\hline Negative urgency & $9.71(2.88)$ & $9.32(2.83)$ & $8.67(3.57)$ & $9.85(2.42)$ & $F=2.46$ \\
\hline Lack of premeditation & $7.69(2.29)$ & $7.81(2.27)$ & $7.32(2.56)$ & $7.94(2.34)$ & $F=0.65$ \\
\hline Lack of perseverance & $7.35(2.39)^{b}$ & $8.10(2.30)^{a}$ & $7.40(2.44)$ & $7.71(2.80)$ & $F=6.37^{* * *}$ \\
\hline Sensation seeking & $8.87(2.82)^{b}$ & $10.14(2.66)^{a, c}$ & $8.72(2.89)^{b}$ & $10.03(2.70)$ & $F=14.56^{* * *}$ \\
\hline
\end{tabular}

Note. ${ }^{*} p<.05,{ }^{* *} p<.01,{ }^{* * *} p<.001 ;{ }^{\mathrm{a}}=$ Statistically significant in comparison to non-users; ${ }^{\mathrm{b}}=$ Statistically significant in comparison to users; $c=$ Statistically significant in comparison to stoppers; ${ }^{d}=$ Statistically significant in comparison to new user.

Table S3. Participants' Characteristics According to Each Profile (Video Games).

\begin{tabular}{|c|c|c|c|c|c|}
\hline & & & Video game & & \\
\hline & $\begin{array}{l}\text { Non-users } \\
M(S D) \text { or } \%\end{array}$ & $\begin{array}{c}\text { Users } \\
M(S D) \text { or } \%\end{array}$ & $\begin{array}{c}\text { Stopper } \\
M(S D) \text { or } \%\end{array}$ & $\begin{array}{l}\text { New users } \\
M(S D) \text { or } \%\end{array}$ & Inferential statistic \\
\hline \multicolumn{6}{|l|}{ Gender } \\
\hline Male & $26.7 \%$ & $58.4 \%$ & $4.1 \%$ & $10.7 \%$ & \multirow{2}{*}{$X^{2}=155.22^{* * *}$} \\
\hline Female & $57.2 \%$ & $22 \%$ & $2.5 \%$ & $18.3 \%$ & \\
\hline Age & $28.09(11.18)^{b, d}$ & $25.03(7.94)^{a}$ & $27.68(11.60)$ & $23.71(6.73)^{a}$ & $F=12.94^{* * *}$ \\
\hline \multicolumn{6}{|l|}{ Lockdown impact } \\
\hline Mental health & $5.05(2.35)^{d}$ & $5.13(2.55)^{d}$ & $5.35(2.80)$ & $5.73(2.20)^{a, b}$ & $F=3.65^{*}$ \\
\hline Personal finances & $4.46(3.09)$ & $4.29(3.07)$ & $4.56(2.91)$ & $4.60(3.01)$ & $F=0.46$ \\
\hline Relationships quality & $3.80(2.52)^{d}$ & $3.96(2.62)$ & $4.18(2.94)$ & $4.44(2.72)^{a}$ & $F=2.76^{*}$ \\
\hline \multicolumn{6}{|l|}{ PANAS } \\
\hline Positive affect & $25.86(7.91)^{d}$ & $24.74(7.62)$ & $25.48(8.23)$ & $23.81(7.40)^{a}$ & $F=3.26^{*}$ \\
\hline Negative affect & $22.25(7.30)^{d}$ & $21.81(7.70)^{d}$ & $21.88(7.00)$ & $25.01(7.64)^{a, b}$ & $F=7.16^{* * *}$ \\
\hline \multicolumn{6}{|l|}{ s-UPPS-P } \\
\hline Negative urgency & $9.49(2.90)$ & $9.50(2.86)$ & $9.33(3.37)$ & $9.96(2.83)$ & $F=1.16$ \\
\hline Lack of premeditation & $7.70(2.26)$ & $7.78(2.37)$ & $7.96(2.67)$ & $7.64(2.20)$ & $F=0.23$ \\
\hline Lack of perseverance & $7.33(2.42)^{b}$ & $7.87(2.25)^{a}$ & $8.41(3.14)$ & $7.63(2.42)$ & $F=4.23^{\star \star}$ \\
\hline Sensation seeking & $8.96(2.87)^{b}$ & $9.54(2.78)^{a}$ & $9.75(2.69)$ & $9.51(2.81)$ & $F=3.43^{*}$ \\
\hline
\end{tabular}

Note. ${ }^{*} p<.05 ;{ }^{* *} p<.01 ;{ }^{* * *} p<.001 ;{ }^{a}=$ Statistically significant in comparison to non-users; ${ }^{b}=$ Statistically significant in comparison to users;

$c=$ Statistically significant in comparison to stoppers; ${ }^{d}=$ Statistically significant in comparison to new user. 


\begin{tabular}{|c|c|c|c|c|c|}
\hline & \multicolumn{5}{|c|}{ Social networks } \\
\hline & $\begin{array}{l}\text { Non-users } \\
M(S D) \text { or } \%\end{array}$ & $\begin{array}{c}\text { Users } \\
M(S D) \text { or } \%\end{array}$ & $\begin{array}{c}\text { Stopper } \\
M(S D) \text { or } \%\end{array}$ & $\begin{array}{l}\text { New users } \\
M(S D) \text { or } \%\end{array}$ & Inferential statistic \\
\hline \multicolumn{6}{|l|}{ Gender } \\
\hline Male & $5.2 \%$ & $90.9 \%$ & $1.7 \%$ & $2.2 \%$ & \multirow{2}{*}{$x^{2}=1.12$} \\
\hline Female & $4.1 \%$ & $92.7 \%$ & $1.3 \%$ & $1.9 \%$ & \\
\hline Age & $36.40(12.50)^{b, c}$ & $25.69(9.14)^{a, d}$ & $28.63(11.17)^{a}$ & $33.00(13.22)^{b}$ & $F=24.53^{* * *}$ \\
\hline \multicolumn{6}{|l|}{ Lockdown impact } \\
\hline Mental health & $4.26(2.28)^{b}$ & $5.25(2.42)^{a}$ & $4.63(2.47)$ & $4.91(2.52)$ & $F=3.09^{*}$ \\
\hline Personal finances & $3.90(3.12)$ & $4.48(3.06)$ & $3.81(2.94)$ & $3.77(2.86)$ & $F=1.13$ \\
\hline Relationships quality & $3.34(2.45)$ & $4.01(2.62)$ & $3.44(2.55)$ & $3.86(2.43)$ & $F=1.27$ \\
\hline \multicolumn{6}{|l|}{ PANAS } \\
\hline Positive affect & $28.31(6.85)^{b}$ & $24.95(7.75)^{a}$ & $26.37(9.70)$ & $26.19(7.72)$ & $F=2.89^{*}$ \\
\hline Negative affect & $21.75(7.80)$ & $22.68(7.54)$ & 19.75 (6.93) & $20.57(7.64)$ & $F=1.47$ \\
\hline \multicolumn{6}{|l|}{ s-UPPS-P } \\
\hline Negative urgency & $9.14(2.90)$ & $9.63(2.88)$ & $9.37(2.94)$ & $8.00(2.88)$ & $F=2.43$ \\
\hline Lack of premeditation & $7.09(2.63)$ & $7.76(2.27)$ & $7.25(2.48)$ & $7.50(2.28)$ & $F=1.45$ \\
\hline Lack of perseverance & $7.14(2.01)$ & $7.62(2.41)$ & $7.43(1.93)$ & $7.00(2.86)$ & $F=0.95$ \\
\hline Sensation seeking & $7.66(2.56)^{b}$ & $9.34(2.82)^{a}$ & $9.25(2.40)$ & $8.85(3.52)$ & $F=4.88^{* *}$ \\
\hline
\end{tabular}

Note. ${ }^{*} p<.05,{ }^{* *} p<.01,{ }^{* * *} p<.001 ;{ }^{\mathrm{a}}=$ Statistically significant in comparison to non-users; ${ }^{\mathrm{b}}=$ Statistically significant in comparison to users; $c=$ Statistically significant in comparison to stoppers; ${ }^{d}=$ Statistically significant in comparison to new user.

Table S5. Participants' Characteristics According to Each Profile (Gambling).

\begin{tabular}{|c|c|c|c|c|c|}
\hline & \multicolumn{5}{|c|}{ Gambling } \\
\hline & $\begin{array}{l}\text { Non-users } \\
M(S D) \text { or } \%\end{array}$ & $\begin{array}{c}\text { Users } \\
M(S D) \text { or } \%\end{array}$ & $\begin{array}{c}\text { Stopper } \\
M(S D) \text { or } \%\end{array}$ & $\begin{array}{l}\text { New users } \\
M(S D) \text { or } \%\end{array}$ & Inferential statistic \\
\hline \multicolumn{6}{|l|}{ Gender } \\
\hline Male & $89.5 \%$ & $2.5 \%$ & $3.6 \%$ & $4.4 \%$ & \multirow{2}{*}{$\chi^{2}=44.71^{\star \star \star}$} \\
\hline Female & $98.1 \%$ & $0 \%$ & $0.9 \%$ & $0.9 \%$ & \\
\hline Age & $26.32(9.80)$ & $30.44(8.66)$ & $27.45(9.62)$ & $25.22(6.77)$ & $F=0.72$ \\
\hline \multicolumn{6}{|l|}{ Lockdown impact } \\
\hline Mental health & $5.20(2.41)$ & $6.33(3.27)$ & $5.00(2.53)$ & $4.78(2.48)$ & $F=0.92$ \\
\hline Personal finances & $4.37(3.04)^{b}$ & $7.44(3.39)^{a}$ & $4.80(3.00)$ & $5.61(3.32)$ & $F=4.30^{* *}$ \\
\hline Relationships quality & $3.95(2.60)$ & $3.44(2.78)$ & $4.45(2.68)$ & $4.74(2.88)$ & $F=1.04$ \\
\hline \multicolumn{6}{|l|}{ PANAS } \\
\hline Positive affect & $25.15(7.78)$ & $22.66(5.04)$ & $28.05(7.42)$ & $23.52(8.09)$ & $F=1.37$ \\
\hline Negative affect & $22.60(7.50)$ & $23.77(8.36)$ & $21.00(8.83)$ & $20.73(8.60)$ & $F=0.69$ \\
\hline \multicolumn{6}{|l|}{ S-UPPS-P } \\
\hline Negative urgency & $9.57(2.91)$ & $9.88(2.80)$ & $9.23(2.46)$ & $9.42(2.43)$ & $F=0.13$ \\
\hline Lack of premeditation & $7.69(2.30)$ & $9.66(2.54)$ & $7.64(1.76)$ & $8.31(2.08)$ & $F=2.62^{*}$ \\
\hline Lack of perseverance & $7.57(2.41)$ & $8.00(1.11)$ & $7.29(1.68)$ & $8.10(2.76)$ & $F=0.47$ \\
\hline Sensation seeking & $9.21(2.85)$ & $11.33(2.44)$ & $9.88(1.57)$ & $9.84(2.67)$ & $F=2.20$ \\
\hline
\end{tabular}

Note. ${ }^{*} p<.05,{ }^{* *} p<.01,{ }^{* * *} p<.001 ;{ }^{a}=$ Statistically significant in comparison to non-users; ${ }^{b}=$ Statistically significant in comparison to users;

$c=$ Statistically significant in comparison to stoppers; ${ }^{d}=$ Statistically significant in comparison to new user. 


\begin{tabular}{|c|c|c|c|c|c|}
\hline & \multicolumn{5}{|c|}{ Online shopping } \\
\hline & $\begin{array}{l}\text { Non-users } \\
M(S D) \text { or } \%\end{array}$ & $\begin{array}{c}\text { Users } \\
M(S D) \text { or } \%\end{array}$ & $\begin{array}{c}\text { Stopper } \\
M(S D) \text { or } \%\end{array}$ & $\begin{array}{l}\text { New users } \\
M(S D) \text { or } \%\end{array}$ & Inferential statistic \\
\hline \multicolumn{6}{|l|}{ Gender } \\
\hline Male & $25.6 \%$ & $41 \%$ & $29.8 \%$ & $3.6 \%$ & \multirow{2}{*}{$\chi^{2}=9.15^{*}$} \\
\hline Female & $19.7 \%$ & $38.3 \%$ & $37.1 \%$ & $4.9 \%$ & \\
\hline Age & $26.54(10.69)$ & $27.78(10.00)^{c}$ & $24.64(8.47)^{\mathrm{b}}$ & $26.18(9.78)$ & $F=7.26^{* * *}$ \\
\hline \multicolumn{6}{|l|}{ Lockdown impact } \\
\hline Mental health & $4.98(2.42)$ & $5.05(2.46)$ & $5.47(2.40)$ & $5.34(2.10)$ & $F=2.93^{*}$ \\
\hline Personal finances & $4.27(3.04)$ & $4.72(3.14)$ & $4.29(3.03)$ & $3.68(2.43)$ & $F=2.84^{*}$ \\
\hline Relationships quality & $3.68(2.51)$ & $3.94(2.59)$ & $4.15(2.65)$ & $4.10(2.84)$ & $F=1.68$ \\
\hline \multicolumn{6}{|l|}{ PANAS } \\
\hline Positive affect & $25.65(8.20)$ & $25.90(7.37)^{c}$ & $23.98(7.73)^{b}$ & $25.60(8.38)$ & $F=4.20^{\star *}$ \\
\hline Negative affect & $22.04(7.58)$ & $22.17(7.60)$ & $23.20(7.52)$ & $22.95(7.06)$ & $F=1.55$ \\
\hline \multicolumn{6}{|l|}{ S-UPPS-P } \\
\hline Negative urgency & $9.25(2.86)$ & $9.89(2.97)$ & $9.35(2.81)$ & $10.04(2.82)$ & $F=3.42^{*}$ \\
\hline Lack of premeditation & $7.71(2.46)$ & $7.71(2.20)$ & $7.65(2.31)$ & $8.39(2.10)$ & $F=1.33$ \\
\hline Lack of perseverance & $7.66(2.64)$ & $7.54(2.31)$ & $7.52(2.35)$ & $7.95(2.36)$ & $F=0.52$ \\
\hline Sensation seeking & $9.33(2.83)$ & $9.31(2.89)$ & $9.10(2.72)$ & 9.79 (3.29) & $F=0.94$ \\
\hline
\end{tabular}

Note. ${ }^{*} p<.05,{ }^{* *} p<.01,{ }^{* * *} p<.001 ;{ }^{\mathrm{a}}=$ Statistically significant in comparison to non-users; ${ }^{\mathrm{b}}=$ Statistically significant in comparison to users; $c=$ Statistically significant in comparison to stoppers; ${ }^{d}=$ Statistically significant in comparison to new user.

Table S7. Participants' Characteristics According to Each Profile (Instant Messaging).

\begin{tabular}{|c|c|c|c|c|c|}
\hline & \multicolumn{5}{|c|}{ Instant messaging } \\
\hline & $\begin{array}{l}\text { Non-users } \\
M(S D) \text { or } \%\end{array}$ & $\begin{array}{c}\text { Users } \\
M(S D) \text { or } \%\end{array}$ & $\begin{array}{c}\text { Stopper } \\
M(S D) \text { or } \%\end{array}$ & $\begin{array}{l}\text { New users } \\
M(S D) \text { or } \%\end{array}$ & Inferential statistic \\
\hline \multicolumn{6}{|l|}{ Gender } \\
\hline Male & $0.3 \%$ & $97.5 \%$ & $1.7 \%$ & $0.6 \%$ & \multirow{2}{*}{$\chi^{2}=4.35$} \\
\hline Female & $0.8 \%$ & $98.3 \%$ & $0.8 \%$ & $0.1 \%$ & \\
\hline Age & $41.71(14.44)^{\mathrm{b}, \mathrm{d}}$ & $26.19(9.55)^{a, c}$ & $34.00(14.26)^{b}$ & $20.33(1.15)^{a}$ & $F=8.95^{\star * *}$ \\
\hline \multicolumn{6}{|l|}{ Lockdown impact } \\
\hline Mental health & $5.29(2.05)$ & $5.21(2.42)$ & $4.25(2.59)$ & $3.33(2.08)$ & $F=1.21$ \\
\hline Personal finances & $5.43(3.15)$ & $4.42(3.06)$ & $4.75(3.25)$ & $3.33(3.21)$ & $F=0.42$ \\
\hline Relationships quality & $3.43(2.50)$ & $3.98(2.61)$ & $3.50(2.78)$ & $2.33(2.30)$ & $F=0.62$ \\
\hline \multicolumn{6}{|l|}{ PANAS } \\
\hline Positive affect & $25.00(8.94)$ & $25.13(7.79)$ & $26.33(6.34)$ & $30.50(4.94)$ & $F=0.41$ \\
\hline Negative affect & $20.50(6.59)$ & $22.63(7.54)$ & $17.00(7.55)$ & $18.00(5.65)$ & $F=2.60$ \\
\hline \multicolumn{6}{|l|}{ S-UPPS-P } \\
\hline Negative urgency & $8.50(2.94)$ & $9.58(2.88)$ & $9.00(3.64)$ & $8.00(1.41)$ & $F=0.63$ \\
\hline Lack of premeditation & $7.33(2.06)$ & $7.72(2.28)$ & 8.08 (3.77) & $7.00(0.00)$ & $F=0.22$ \\
\hline Lack of perseverance & $6.00(1.67)$ & $7.59(2.40)$ & $7.41(2.57)$ & $6.50(0.70)$ & $F=1.03$ \\
\hline Sensation seeking & $9.00(1.78)$ & $9.25(2.84)$ & $9.58(3.31)$ & $11.00(2.82)$ & $F=0.31$ \\
\hline
\end{tabular}

Note. ${ }^{*} p<.05,{ }^{* *} p<.01,{ }^{* * *} p<.001 ;{ }^{\mathrm{a}}=$ Statistically significant in comparison to non-users; ${ }^{\mathrm{b}}=$ Statistically significant in comparison to users;

$c=$ Statistically significant in comparison to stoppers; ${ }^{d}=$ Statistically significant in comparison to new user. 
Correspondence to:

Jesús Castro-Calvo

Department of Personality, Assessment, and Psychological Treatments, Faculty of Psychology, University of Valencia

Av. Blasco Ibáñez, 21

València, 46010

Spain

Email: jesus.castro(at)uv.es

Editorial record: First submission received on September 29, 2020. Revision received on June 15, 2021. Accepted for publication on August 19, 2021.

Editor in charge: David Smahel 


\section{About Authors}

Alfredo Zarco-Alpuente is a master's student in Clinical Psychology at the University of Valencia. Her research interests include adolescent' prosocial and antisocial behaviour, sleep, and behavioural addictions.

Víctor Ciudad-Fernández is a master's student in Psychology of Addiction at the University of Valencia. His research interests include substance abuse and behavioral addictions (mainly, technology-related problems).

Dr. Rafael Ballester-Arnal is a Full Professor in the Department of Basic and Clinical Psychology and Psychobiology at the Jaume I University (Spain). He is involved in multiple research projects concerning different aspects of sexual health, such as pornography abuse, assessment and treatment of cybersex addiction, sexual diversity, and sexuality in adolescent and young sex offenders.

Joël Billieux is associate professor of clinical psychology, psychopathology, and psychological assessment at the university of Lausanne, and Research Unit Director of the Cognitive and Affective Regulation Lab (CARLA), Institute of Psychology (IP), University of Lausanne (UNIL). His main area of research regards the psychological factors (cognitive, affective, motivational, interpersonal) involved in the etiology of addictive behaviors, with a particular focus on self-regulation-related processes. Another focus of his research is the conceptualization and diagnosis of behavioral addictions. More recently, he also conducted research focusing on the effect of emerging technologies on human behavior.

Dr. María Dolores Gil-Llario is a Full Professor in the Department of Developmental and Educational Psychology at the University of Valencia (Spain). She leads research projects exploring different aspects of human sexuality, mainly sexting among adolescents, sexuality in minors under social protection measures, and the promotion of sexual health in people with intellectual disabilities.

Daniel L. King is an Associate Professor and clinical psychologist in the College of Education, Psychology, and Social Work, Flinders University, Australia. His research focuses on understanding and responding to digital technology-based problems, particularly those related to online gaming and simulated gambling.

Inma Montoya-Castilla, PhD, is an Associate Professor in the Faculty of Psychology at University of Valencia. Her research focuses on Emotional education in different populations (childhood and adolescence, adolescents, teachers, couples, etc.) and in different contexts (mainly educational and health). She also leads a line of research focused on affective-sexual and gender diversity.

Paula Samper, PhD, is an Associate Professor in the Faculty of Psychology at University of Valencia. Her research focuses on adolescents and aggressive and prosocial behavior. She is interested in the analysis of variables which are related with these two kinds of behavior: family, emotions, peers, school, society.

Dr. Jesús Castro-Calvo is an Assistant Professor in the Faculty of Psychology at the University of Valencia (Spain). His research interests focus on the assessment and treatment of behavioral addictions (mainly, problematic pornography use).

(c) Author(s). The articles in Cyberpsychology: Journal of Psychosocial Research on Cyberspace are open access articles licensed under the terms of the Creative Commons BY-NC-ND 4.0 International License which permits unrestricted, non-commercial use, distribution and reproduction in any medium, provided the work is properly cited. 